Citation: Kessenikh A. (2021) Spin Temperature and Dynamic Nuclear Polarization. From the History of Researches (1949-1983). Substantia 5(2): 19-34. doi: 10.36253/Substantia-1224

Received: Feb 19, 2021

Revised: Jul 05, 2021

Just Accepted Online: Jul 06, 2021

Published: Sep 10, 2021

Copyright: @ 2021 Kessenikh A. This is an open access, peer-reviewed article published by Firenze University Press (http://www.fupress.com/substantia) and distributed under the terms of the Creative Commons Attribution License, which permits unrestricted use, distribution, and reproduction in any medium, provided the original author and source are credited.

Data Availability Statement: All relevant data are within the paper and its Supporting Information files.

Competing Interests: The Author(s) declare(s) no conflict of interest.
Feature Articles

\section{Spin Temperature and Dynamic Nuclear Polarization. From the History of Researches (1949-1983)}

\author{
Alexander Kessenikh \\ S.I. Vavilov Institute for History of Science and Technology, Russian Academy of Science, \\ Moscow, Russia \\ E-mail: kessen32@mail.ru; ORCID: 0000-0001-8727-4642
}

\begin{abstract}
An attempt is undertaken to acquaint the reader with a history of research and applications of dynamic nuclear polarization (DNP) in the most concise form the main focus on the first three decades of DNP research, and the history of the discovery and development of multiparticle DNP and its relationship with the spin temperature approximation are outlined in some detail. The article emphasizes the role of such researchers as Anatol Abraham, Maurice Goldman, Michel Borghini, Thomas Wenckebach, Vadim Atsarkin, Boris Provotorov, Maya Rodak, Mortko Kozhushner, Levan Buishvili, Givi Khutsishvili. As far as possible, the contributions of many other scientists are considered. The establishment of a uniform temperature for nuclear spins due to the effect of spin diffusion was first proposed by Nicholas Blombergen in 1949. The content of the article is based on the bibliography available in the public domains, in particular on the memoirs of the research participants, and first of all on the materials of Atsarkin's 1978 review in Sov. Phys. Uspekhi and on the oral history of the development of the multiparticle concept of DNP effects, collected from the speeches of the participants of the Moscow seminar "Problems of Magnetic Resonance" in 2001. A simplified description of the effects of DNP and a summary of the history of their discovery is given in section "Introduction". The brief biographical data and portraits of participants in the DNP study are given in Appendix 1, and a selected bibliography on the problems of DNP and spin temperatures is given in Appendix 2. The bibliography divided into four sections according to the time and type of publication (I - historical research, memoirs; II - monographs, reviews; III - original publications 1953 - 1983; IV - some original publications of a later time, mainly during the transformation of DNP into an method for the implementation of nuclear magnetic spectroscopy and tomography in the interests of chemistry, biochemistry and medicine). The widespread use of DNP methods is evidenced, for example, by the fact, that by now company Bruker BioSpin has installed about 50 gyrotron based spectrometers for DNP operating up to $593 \mathrm{GHz}$ worldwide to date.
\end{abstract}

Keywords: Magnetic Resonance, Dynamic Nuclear Polarization, Nuclear Spin. 


\section{INTRODUCTION}

\subsection{General remarks}

The degree of polarization is determined by the relative excess among the spins of some type such a one with a lower energy of interaction with the magnetic field. Therefore, this configuration is stable. The lower a lattice temperature $T_{L}$ is, the greater an excess of spins at the lowest quantum levels. The higher the induction of the magnetic field in which the sample is located, the higher the degree of polarization. The increasing of magnetic field's induction $B_{0}$ causes enhancement of polarization. This method of increasing polarization was once called the "brute force method". The increase in polarization with decreasing lattice temperature is also natural. That is why experiments with polarized nuclei at low absolute temperatures $T_{L} \leq 4.2 \mathrm{~K}$ are so widespread. The thermal polarization $P_{S 0}$ regardless of $T_{L}$, for example, for spins $S=1 / 2$ is equal to:

$\mathrm{P}_{S 0}=\tanh \left(\frac{\gamma_{S} \hbar B_{0}}{2 k T_{L}}\right)$

Hereafter $\gamma_{S}$ is the gyromagnetic ratio for electron spins, $\gamma_{I}$ is the gyromagnetic ratio for nuclear spins, $\hbar=$ $h / 2 \pi$ is the Planck constant, $k$ is the Boltzmann constant. The total paramagnetic moment of each type of spins $I=1 / 2$ with a total number $N$ and gyromagnetic ratio $\gamma_{I}$ and magnetic moment $\mu_{I}$ under conditions of interaction with lattice located at the absolute temperature $T_{L}$ is equal ( for $\mu_{I} B_{0}<<k T_{L}$ ) to:

$\mathrm{M}_{0}=\frac{\left(\gamma_{I}^{2} \hbar^{2} N B_{0}\right)}{2 k T_{L}}=\mu_{I} P_{I}$

However, it turns out to be possible, using magnetic resonance and other "pumping" methods, to create quasi-equilibrium configurations with anomalous depletion of the lower levels or even with an excess of spins at higher energy levels. It is dynamic nuclear polarization (DNP). Under conditions of continuous action of an alternating electromagnetic field with a frequency close to the ESR resonance of paramagnetic centers (PC), the Zeeman system of nuclear spins takes on a temperature $T_{I}$ that differs from the lattice temperature, and therefore:

$\left|M^{*}\right|=\eta M_{0}=\frac{\left(\gamma_{I}^{2} \hbar^{2} N B_{0}\right)}{2 k T_{I}}$

where $\eta \leq \frac{\gamma_{S}}{\gamma_{I}}$ is "the enhancement coefficient" or enhancement of nuclear polarization. The dynamic nuclear polarization for nuclei with $\gamma_{I}$ may be of the order of thermal electron polarization for PC with $\gamma_{S}$.

For an arbitrary spin number $I$, the corresponding values of the total magnetic moment and, therefore, the integrated intensity of the NMR signal are [Abragam. II.1961. Chapter VIII]:

$\mathrm{M}_{0}=\frac{\left(\gamma_{I}^{2} \hbar^{2} N B_{0} I(I+1)\right)}{3 k T_{L}}$
$\left|\mathrm{M}^{\star}\right|=\frac{\left(\gamma_{I}^{2} \hbar^{2} N B_{0} I(I+1)\right)}{3 k T_{I}}$

Anomalous polarization is characterized in conditions DNP (in the simplest case relatively high temperatures) by formula (3a), similar to (2a), but with the positive or negative inverse temperature of the nuclear Zeeman system possibly much more in absolute value than the inverse lattice temperature) $\left|T_{I}\right|^{-1}>>\left(T_{L}\right)^{-1}$.

Methods of dynamic polarization of nuclei employing ESR saturation began to develop in 1953. The mechanism of DNP was discovered and elementary magnetic resonance acts of one kind of electron spins $S$ directly interacting with nuclear spins $I$ was studied (Overhauser effect (OE) [Overhauser. III. 1953A;1953B; Carver and Slichter. III.1953]). The processes were discovered soon [Abraham M., Kedzie, Jeffries III.1957] with a saturation of the combined resonance $A_{( \pm)(\mp)} S_{\mp} I_{ \pm}$of the spins of two particles (an electron and one of the nuclei). In the so called solid effect (SE), the result is achieved due to the microwave-induced forbidden electron-nuclear transitions $A_{(z)( \pm)} S_{z} I_{ \pm}$, when each of the transitions two spins: $S$ and $I$. The latter DNP mechanism is effective for solid dielectrics with a high density of polarized nuclei $I$ (see below about nuclear spin diffusion) and was discovered by Abragam [Abragam, Proctor. III. 1958]. In previous formulas $A_{(i)(k)}$ are the components of hyperfine interaction tensor.

Later (1963-1967), the mechanisms were observed evidently with excitation of processes involving three spins (two electron and one nucleus, so called "electronnuclear cross-relaxation" (ENCR) or cross-effect (CE)) through saturation on the wings of the ESR lines [Kessenikh et al. III.1963; Hwang and Hill. III.1966A; 1966B].

The DNP mechanisms involving many electron spins were discovered almost simultaneously (1962 1968). In such mechanisms of nuclear polarization, the so-called thermal mixing (TM) and dynamic cooling (DC) DNP occurs due to the transfer of collective energy of electron spin-spin interactions, i.e., we are faced with an essentially multiparticle effects [Abragam, Borghini. III.1962; Provotorov, Kozhushner. III. 1967]. This was immediately confirmed in the important experiments performed by Atsarkin, Mefed, Rodak [Atsarkin et al. III.1967], by Dutch physicists [Wenckebach et al. III.1968; 1970], and by French physicists. The detailed analysis of the relationship between TM and CE is given 
by Wenckebach (see [Wenckebach II.2016; IV.2017; IV. 2019A;2019B]. The first steps of discovery and mastering of these two late DNP mechanisms were considered in the article [Atsarkin, Kessenikh. I.2012]. If we talk about dynamic polarization through the excitation of transitions between mixed electron-nuclear states, then this effect is provided usually by the nuclear spin diffusion inside the array of matrix nuclei (see for example [Khutsishvili.III. 1954; Khutsishvili.II.1968]), although it also manifests itself on the nuclei of the substance dissolved in the matrix. It should be noted that the diffusion mechanism of nuclear spins in a solid-state matrix was first suggested by N. Blombergen before the discovery of DNP processes [Blombergen. III.1949].

When the dipole-dipole and exchange interactions in the system of electron spins of the paramagnetic centers (PC) are sufficiently large and their energy is at least comparable to the energy of effects leading to inhomogeneous ESR broadening, the effects of dynamic cooling (thermal mixing) with a multiparticle transfer of polarization from the electron spin-spin reservoir to the nuclear Zeeman system come to the fore in the DNP mechanisms.

\section{THE THERMAL MIXING OR DYNAMIC COOLING. UNDER THE SIGN OF PROVOTOROV'S THEORY}

The mechanisms of DNP and related phenomena discovered or predicted earlier remained in the repertoire of researchers and were successfully developed further. The Overhauser effect in nuclear spin systems with different resonant frequencies has become an almost routine method in nuclear magnetic resonance [Noggle., Schirmer. II.1971.]. Numerous studies in weak magnetic fields (up to the induction of Earth's magnetic field) have also been partially based on the Overhauser effect. The "solid effect" discovered by A. Abragam was successfully used for proton polarized targets. Separate studies of the three-spin ENCR (CE) mechanism have also been performed. However, the main direction of research on DNP and related phenomena in the 1960s-1970s was the study of the effects of thermal mixing of the nuclear Zeeman system with the subsystem of dipole-dipole interactions of electron spins discovered by Boris Provotorov.

Anyone who dealt with the problems of magnetic resonance in the 60s-70s will immediately remember what works [Provotorov. III.1961; Provotorov. III.1962] mean and what role they played in the development of this field of science.

The essence of Provotorov's theory is that there exist an inverse temperature and one more inverse tempera- ture, which are the inverse temperatures of the Zeeman interaction and the dipole-dipole interaction. The concept of two temperatures is applicable both in a coordinate system rotating with the frequency of a radio-frequency field and in a laboratory coordinate system, and the schools of A. Abragam - M. Goldman and A. Redfield (see classical monographs [Goldman.II.1970; Abragam and Goldman.II.1982]) predominantly use a rotating system coordinates. The relationship between the inverse temperatures of the two reservoirs is determined by Provotorov's equations. Here is the record of Provotorov's equations in the classic monograph by M. Goldman in the laboratory system:

$\frac{d \alpha^{\prime}}{d t}=-W\left\{\alpha^{\prime}-\frac{\Delta}{\omega_{0}} \beta\right\} ; \frac{d \beta}{d t}=W \frac{\Delta}{D^{2}}\left(\omega_{0} \alpha^{\prime}-\Delta \beta\right)$

where $\Delta=\omega_{0}-\omega$ (detuning the microwave frequency $\omega$ from resonance); $D=\gamma H_{L}$, - the average shift of the resonance frequency of each of the dipoles in the local field $H_{l}$ (that is, in the field caused by neighboring dipoles); Factor proportional to the square of the amplitude of the resonant magnetic field $W=\pi \omega_{1}^{2} g(\Delta)$ - the probability of transition between spin magnetic sublevels under the influence of a rotating magnetic field with amplitude $H_{1}=\frac{\omega_{1}}{\gamma}$, where $g(\Delta)$ - line shape function. The prime at $\mathrm{a}^{\prime}=\frac{1}{T_{S Z}}$ in Goldman text corresponds to the Zeeman temperature in the laboratory system, while the author of [Goldman. II.1970] and his immediate colleagues consider most of the problems in a rotating coordinate system. The value $\beta=\frac{1}{T_{S S}}$ is a inverse temperature of spinspin reservoir introduced in Provotorov's works.

It should be stressed for formal thermodynamics that the revolutionary idea of Provotorov was to assign two temperatures to a single system of spins. This was theoretically a controversial innovation, especially because - except in the high temperature approximation-these two temperatures cannot be assigned to two separate energy reservoirs. J.Philippot - [Philippot. III.1964], considered the inverse Zeeman temperature as a chemical potential and the inverse dipolar interaction temperature as the real inverse temperature.

The method of two reservoirs proposed by Provotorov for a system consisting of one kind of spins turned out to be extremely fruitful. This method is suitable both for systems with several resonance lines, and for spin systems with spins of different types, with sharply differing values of gyromagnetic ratios. The case when the resonance frequency of spins with a low $\gamma_{I}$ value is close to the width of the resonance line of spins with high $\gamma_{S}$ is especially interesting.

Wenckebach in his article [Wenckebach. IV.2019B] points out the approximation of the fluctuating field 
introduced by Buishvili [Buishvili. III.1965 - 1966], Provotorov and Kozhushner [Provotorov and Kozhushner. III.1967; Kozhushner. III.1969] and subsequently further developed by Goldman [Goldman et al. IV.1974] — the case of generalized approach taking into account the interaction of nuclear spins with the whole dipole reservoir of electron spins. The version of the multiparticle DNP mechanism was the most popular in 1960s years. Note that Soviet researchers in the 60 s and partly $70 \mathrm{~s}$ accounted for at least $20 \%$ of that invisible college that dealt with the problems of spin temperatures and spin polarizations. Of those who were directly involved in the development and experimental verification of Provotorov's theory, mention should be made primarily of Mortko Kozhushner, Oleg Olkhov from the Institute of Chemical Physics, Maya Isaakovna Rodak, Vadim Atsarkin, Anatoly Yegorovich Mefeod, Sergey Morshnev et al from the Institute of Radio Electronics of the USSR Academy of Sciences (USSR AS), as well as Georgian physicists Givi Khutsishvili, Levan Buishvili, Mikhail Zviadadze et al.

The influence of both the above-cited and subsequent articles of Boris Provotorov on the development of theoretical and experimental work in the field of magnetic resonance in the 1960s and 1970s was very important and their significance has survived to this day. In 2001, the All-Moscow Seminar "Problems of Magnetic Resonance" under the direction of V.A. Atsarkin devoted his 158th meeting to the fortieth anniversary of Provotorov's first works (see the publication of the abridged transcript of the seminar [NMR, EPR and theory of condensed systems of magnetic dipoles. I. 2004]). Boris during the execution of his pioneer works was a young employee of the theoretical group headed by A.S. Kompaneets at the Institute of Chemical Physics of the USSR AS. Boris did not hide the fact that he was significantly influenced by the work of Alfred Redfield (USA) devoted to the saturation of magnetic resonance [Redfield. III.1955].

In continuation and development of the successes of French physicists, Provotorov's ideas were picked up and developed by Maurice Goldman and Anatole Abragham with Michel Borghini. Already before 1964, Abragam and Borghini published the results of the implementation of the Provotorov's idea on existence of the electron spin-spin (SS) reservoirs and the implementation of a new DNP mechanism. In Atsarkin's article [Atsarkin. 1978] the results of the application of Provotorov's theory included in the actually review work of Abragam and Borghini [Abragam and Borghini. II.1964] are formulated as one of the options for thermal mixing (compare the Fig.1): Under conditions of microwave pumping

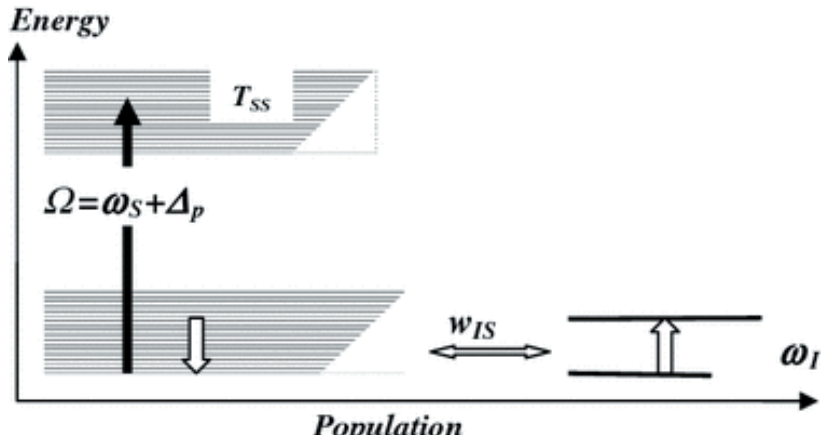

Figure 1. Diagram of the mechanism of induced thermal mixing according to Abragam - Borghini [([Atsarkin. II.1978]). See text for explanation.

at frequency $\Omega=\omega_{S}+\Delta_{p}$ which saturates the ESR line with a small offset $\Delta_{p}$ from the resonance, the values of $\beta_{\mathrm{SZ}}$ and $\beta_{S S}$ become quite different. Whereas the Zeeman subsystem is heated ( $\beta_{S Z}$ decreases but remains positive), the inverse temperature $\left|\beta_{s s}\right|$ value increases dramatically, reflecting strong change in the mean energy of the secular dipole-dipole interactions. The strong cooling of the SS reservoir is represented in Fig. 1 by a steep Boltzmann distribution of populations inside the SS band.

In the frames of the quasi-equilibrium model, this phenomenon is explained by the transfer of the energy $|\hbar \Delta p| \cdot \hbar \Delta p$ to (at $\Delta_{p}>0$ ) or from (at $\Delta_{p}<0$ ) the SS reservoir at every act of quantum absorption. In the former case, particularly, the upper levels of the SS band are overpopulated and $\beta_{S S}$ is negative, see Fig. $\underline{1}$. Here is a diagram of the induced thermal mixing mechanism. Horizontal bars reflect populations of corresponding energy levels in the electronic (left) and nuclear (right) systems. The arrows show transitions induced by the microwave pumping (black) and electron-nuclear dipolar interactions (light).

We add, using the valuable remark of the head of the 2001 seminar V.A. Atsarkin (see [NMR, EPR and theory of condensed systems of magnetic dipoles. 2004]), that the French physicists a year before the appearance of the work [Provotorov. III.1961] seemed to have anticipated Provotorov's ideas about two energy reservoirs in the spin system. Atsarkin said: "Their experiment [Goldman and Landesman. III.1961] was carried out in such a way that in a weak field saturates the quadrupole resonance of chlorine isotopes (in paradichlorobenzene), thereby shifting the dipole temperature in the common dipole reservoir of chlorine and protons. Then the field was introduced adiabatically, and a signal of protons was enhanced (a kind of DNP). Goldman writes [Goldman.I.1996] - he carried out the experiment 
- writes that when they got this result, they still doubted how all this could be explained, but there was L. Solomon, who explained this phenomenon to them in the mentioned way. I would not want a dispute about priorities to arise here, because in fact, I must honestly admit that Abragam dealt with spin temperature much earlier than all of us put together. And, of course, people absent here at the seminar, French physicist, they have the same memories. Therefore, when discussing priorities, one must understand all this. Of course, Abragam's laboratory at Saclay was the research engine of the spin temperature, and they thought a lot on this issue there".

French physicists evidently again proved to be at the forefront in mastering new approaches to the theory and method of DNP. But their Soviet colleagues in this time did not fall behind them significantly. The idea of Kozhushner and Provotorov about the direct contact of an SS reservoir with a nuclear Zeeman (IZ) reservoir was formulated in 1964 at a conference on magnetic resonance in a solid, held in Krasnoyarsk. The publication [Kozhushner and Provotorov.III.1967] was, however, delayed due to purely technical reasons, but its result was already known and even actually experimentally confirmed in the works of Rodak, Atsarkin, Mefeod, Morshnev, Ryabushkin ( see also [Kozhushner. III.1969]). Intensive research towards the approval of the two-reservoir theory of spin temperatures including the study of systems with number of lines in ESR spectrum [Atsarkin et al. III.1967] was initiated by Maya Rodak at the Institute of Radio Electronics of the USSR Academy of Sciences (USSR AS).

Let us to say a few words about the exceptional role of Maya Rodak in the development of Provotorov's theory. Magnetic resonance data make it possible to measure not only the Zeeman temperature, but also the spin-spin temperature, as was shown in the series of Provotorov's works. The integral intensity of the spectral line of magnetic resonance absorption serves as a measure of the Zeeman spin temperature (this is well known), and the shape of the contour of the magnetic resonance absorption line makes it possible to establish the spin-spin temperature (this fact in itself and the algorithm for such determination were the subject of works by Provotorov and his followers). But Rodak first developed a detailed theory of the experimentally observable and wellexpressed effect (induced radiation in a part of ESR line) under saturation conditions in 1964 [Rodak. III.1964]. At the same year Provotorov and his disciple Mortko Kozhushner put forward the idea of thermal mixing of electron spin-spin and nuclear Zeeman systems. Due to this mixing, the inverse temperature of the nuclear Zeeman reservoir will tend to the inverse temperature of the electron dipole-dipole reservoir (dynamic cooling). Maya Isaakovna recalled in 2001 at the seminar "Problems of magnetic resonance" two conferences Colloque AMPERE in Ljubljana - 1966 and Colloque AMPERE in Grenoble - 1968, where she was a "scientific tourist":

"I brought to Ljubljana a small calculation from a series of physical consequences of Provotorov's theory. Here I should note that when Boris Nikitovich and I met at the beginning of 1963, I brought him a calculation just for cross-relaxation. It was simply striking that cross-relaxation draws energy from the dipole-dipole spin-spin reservoir. And in parallel with this, at saturation on the wing of the line, the same spin-spin reservoir is also touched, its temperature changes. These two processes can be somehow related and by changing the detuning and saturation on the wing, you can probably influence cross-relaxation. I was very happy when he accepted my calculation well. And then he immediately recommended my work at Soviet JETP, and we established good relations. But by 1966, even in the fall of 1966, when the Colloque AMPERE was in Ljubljana, we did not have an experiment. And all these four years, quite a lot of effects were predicted, which, from the point of view of the experiment, seemed not at all easy. Like Provotorov, I was confronted with mistrust all the time ... For this reason, this trip to Ljubljana was very important for me, because I saw a completely different attitude of our foreign colleagues there. So, even on the eve of the congress, in the evening at such a cocktail party, where all the participants got to know each other, J. Jeener came up to me. He was a professor at the University of Brussels, a serious theorist of the Prigozhin school and at the same time a skillful experimenter ... So he came up, said that he was interested in Provotorov's theory, read my articles, requested me to send them. It was Jeener who responded to Provotorov's very first publications with a large article entitled "Thermodynamics of spin systems in solids", which appeared in Phys. Rev. in 1964 [Jeener et al. III. 1964.], and he sent it to Provotorov as a preprint back in 1963, this proves his benevolence. In this article, he not only brilliantly outlined the physical foundations of Provotorov's theory from a general standpoint, but also presented the data of his experiments. These experiments were on harmonic cross-relaxation of nuclear spins in lithium fluorine (lithium fluoride) and it turned out, contrary to old ideas, that the tendency of cross-relaxation is by no means the establishment of a single temperature. The temperatures turned out to be different, and the more volatile spin-spin temperature changed most sharply.

After my report on the "Theory of Magnetic Resonance" section [Rodak. III.1967], Redfield approached 
me. I was told that his classic work 1955 was his graduate thesis. And by the time of our meeting he was already an internationally recognized scientist. As you know, in this classic work of his, he described magnetic resonance in a solid at strong saturation. Provotorov does not require saturation at all; he has a different criterion: the smallness of the alternating field in comparison with the local one. And Redfield, therefore, rightly, back in 1963, noted that Provotorov - these are literally his (Redfield's) words - “...filled the gap that existed in the theory of magnetic resonance in solids - threw a bridge across the gap." As far as I remember, in his famous book Abragam even writes directly that for $H_{1}$, for a variable field much smaller than the local one $H_{l o c}$, the question remains, so the theory is by no means complete.

Abragam actually opened the congress. He made the first plenary lecture on the dynamic polarization of nuclei [Abragam. III. 1967], by the way, he did it in French, apparently in opposition to the Americans. Half of the audience did not understand him. Our entire delegation got to know him while walking around Ljubljana, it was facilitated by the fact that he knows Russian perfectly. Afterwards, we talked more than once, and at the end I dared to complete the task that Boris Nikitovich gave me, he was very angry with Abragam, and I decided to reconcile them. And so I just asked him why he had not responded in any way to the first work that Boris had given him in the fall of 1961 in the form of typescript. Abragam, as was typical for him, said that he did not understand anything. And then he noticed that he also did not understand and appreciate the classic work of Redfield at first. I would also like to remind you that there were several physicists who by this time, although they were not represented at AMPERE, worked in the same direction as Provotorov. They did conduct experiments, among them Goldburg, work in 1962 [Goldburg. III.1962]. All of them referred to Provotorov ... Franz and Slichter - later works of 1966 [Franz and Slichter. III. 1966] and, of course, Goldman, who in 1964 in the French Journal de physique [Goldman. III.1964] introduced the term "Provotorov theory", and later used it many times.

So, by 1966, our foreign colleagues recognized Provotorov's theory and were very interested in it, at a time when, as we know, and as it was said at our seminar, many of our Russian colleagues had a lot of objections against Provotorov's theory, up to 1966».

In 1968 Maya Isaakovna had already brought to the AMPERE meeting the results of the experimental work she initiated. Rodak herself and their co-authors and colleague confirmed the effects expected from the results

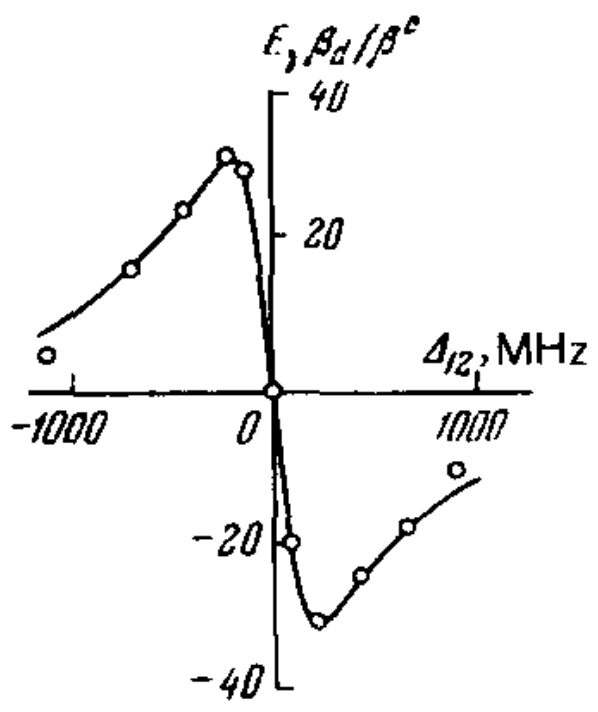

Fig. 2. Enhancement of polarization of ${ }^{27} \mathrm{Al}$ ( $\eta$, here $\mathrm{E}_{\mathrm{f}}$,open circles) and degree of DDR cooling $\beta_{S S} / \beta_{L}$ (here $\beta_{d} / \beta_{0}$, solid curve) as a function of the detuning $\Delta_{12}$ between the two ESR lines involved in the cross-relaxation (one of them is saturated by the high-frequency field) [Atsarkin et al- III 1969].]. $\mathrm{Al}_{2} \mathrm{O}_{3}$ crystal with $0.03 \%$ of $\mathrm{Cr}^{3+}$, $T^{\circ}=1.9^{\circ} \mathrm{K}, B_{0}=0.33 \mathrm{Tl}$.

of Provotorov. Among the results reported in Grenoble were data on an explicit connection between electronic cross-relaxation (and hence the temperature of the spinspin reservoir) and the dependence of the nuclear polarization enhancement on the frequency of microwave irradiation of a ruby sample, which has two well-resolved lines in the EPR spectrum at frequencies close to 10 GHz. For these data see works [Atsarkin et al. III.1967; Atsarkin et al. III.1968] (see Fig. 2)

A group of Dutch physicists began the DNP research [Swanenburg et al.1967]. Similar and very interesting results on induced thermal mixing of nuclear Zeeman reservoir with dipole electron-electron reservoir in DNP were obtained at 1968 and later. The future classic of DNP W.T. Wenckebach joined to this group and took part in verification of direct DC mechanism [Wenckebach et al.III.1968, Wenckebach et al.III.1969] too. They studied the so-called Tutton salts $\mathrm{ZnK}_{2}\left(\mathrm{SO}_{4}\right)_{2} \cdot 6 \mathrm{H}_{2} \mathrm{O}$ with an admixture of paramagnetic copper-II ions, where the ESR spectra have a hyperfine structure due to the scalar interaction of electron spins with nuclei of isotopes ${ }^{63.65} \mathrm{Cu}$. These studies were continued successfully ([Hoogstraate et al. III.1973; Wenckebach et al. III. 1974] etc). An interesting result was obtained by comparing the DNP pattern in such samples at $14 \mathrm{~K}$ and $1.5 \mathrm{~K}$. This experiment was also described in the review [Atsarkin. II.1978] (see Fig.3 from review). To some extent, the 

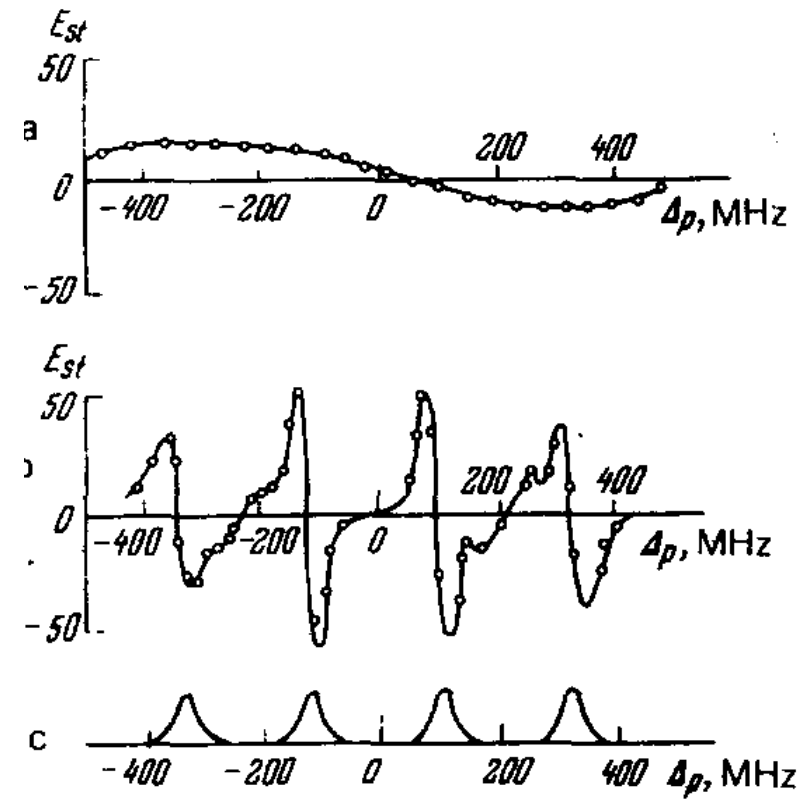

Fig. 3. Enhancement of polarization of protons $\eta$ (here Est) in a crystal of $\mathrm{ZnCs}_{2}\left(\mathrm{SO}_{4}\right)_{2} \cdot 6 \mathrm{H}_{2} \mathrm{O}$ with $0.5 \%$ of $\mathrm{Cu}^{2+}$ as a function of the detuning $\Delta_{p}$ of the high-frequency field relative to the center of gravity of the ESR spectrum $\left(B_{0} \approx 0.3 \mathrm{Tl}\right)$ [Wenckebach et al. 1974]: (a) $\mathrm{T}^{\mathrm{b}}=1.5^{\circ} \mathrm{K}$, (b) $=14^{\circ} \mathrm{K}$, (c) ESR spectrum of the $\mathrm{Cu}^{2+}$ ion.

averaging of the obtained polarization over all possible dipole cross-relaxation effects as the electron spin-lattice relaxation time increases with decreasing absolute temperature, which is obvious from the figure, reminds of a similar effect in irradiated polyethylenes. Such an averaging (and there merge of maxima) leads to an effect that we call "spreading of the DNP maxima" [Kessenikh. et al. III.1964] and, of course, to a sharp decrease in the polarization enhancement.

\section{SOME RESULTS OF EARLIER PERIOD AND FURTHER DEVELOPMENT OF DNP RESEARCH}

3.1. Results of the first three decades of research on the effects of DNP. Leadership of French physicists and contribution of Soviet researchers

The first period of DNP research, in our opinion, ends by the early 1980 s, but it makes no sense to indicate a more precise date than, say, the date of publication of a fundamental review [Atsarkin. II. 1978], and then a monograph [Atsarkin. II.1980], that, unfortunately was not translated into English. The 1970s, and early 1980s were also marked in the history of the DNP by the editions of more famous monographs [Goldman. II.1970] and [Abragam \& Goldman. II.1982]. In the Soviet Union, by the 1960s and early 1970s, there was a fairly significant cohort of researchers of DNP and other phenomena studied in the spin temperature approximation. The works of the scientific schools in field of magnetic resonance in the Institute of Radio Engineering and Electronics, the Institute of Chemical Physics and the Institute of Physics of the Georgian Academy of Sciences made a significant contribution to the development of ideas about DNP and are wide known. The important results of applications of the DNP method to the study of nuclear reactions were obtained at the Joint Institute for Nuclear Research in Dubna. Research on DNP in the late 1960s-1970s and up to the mid-1980s continued to be most successful in France. The Saklay Nuclear Research Center has become a real Mecca for DNP specialists. As a remarkable example of the unification of scientific forces from different European countries under the auspices of the Saclay Center, we cite a link to the work of the ever-memorable for Czechoslovakia 1968 with the coauthorship of the Soviet specialist V.I. Lushchikov and Czech Odehnal on the DNP of protons in lanthanummagnesium nitrate with a paramagnetic impurity of dysprosium ions [Odehnal, Loutchikov and Ezratty. III.1968]. In the late 1960s and early 1970s, unique research led by Abragam and Goldman (partially with the participation of the Dutch physicist Wenckebach). These researches led to the achievement of almost $100 \%$ polarization of fluorine nuclei in a single crystal of lithium fluoride, which made it possible to observe phase transitions of the spin system of nuclei into magnetically ordered states - nuclear ferromagnetism and nuclear antiferromagnetism [Chapellier. Goldman. Chau. Abragam. III. 1969; Jacquinot, Wenckebach, Chapellier, Goldman, Abragam. III. 1974] etc.

Japanese an American physicist Akira Masaike recalls at 2014 the role of Abragam's disciple Michel Borghini in the development of DNP methods for high energy physics [Masaike. I.2016]: «High energy spin physics began in early 1960s. It was pointed out that studying the spin dependent forces is one of the most important issues for particle physics. Therefore, it became an urgent need to measure the spin parameters of particle reactions. In order to realize such an experiment, it was indispensable to polarize the target protons...

The success of the dynamic polarization was amazing-event for high energy physicists, since it promised a new field of particle physics. At the International Conference on Polarized Targets held at Saclay in 1966, the known Australian physicist R. H. Dalitz pointed out that the polarized target may lead to especially illuminating information on three major areas in particle physics: 
(i) High energy scattering where Regge-pole exchange is dominant.

(ii) Tests of time-reversal invariance for electromagnetic processes.

(iii) Hadron spectroscopy. Many resonant states had been observed for mesonic and baryonic states. In the attempt to classify and understand these hadronic states, the first need is for the determination of the spin and the parity for each state.

The first experiment with the polarized target was performed to measure the correlation parameter $C_{n n}$ for p-p scattering at $20 \mathrm{MeV}$ by Abragam, Borghini, Catillon P., Coustham J., Roubeau P. and Thirion J. at Saclay in 1962 [A. Abragam et al. III. 1962]. The experiment was done with a polarized beam on polarized protons in LMN. The first pion-proton scattering experiment was performed at Berkeley (Bevatron) by Chamberlain, Jeffries, Schutz, Shapiro, and van Rossum in 1963 [Chamberlain O. et al. III. 1963.] In this experiment it was necessary to measure both angles of pion and proton in order to check the coplanarity, since the background from complex nuclei were enormous. Neutron transmitted through polarized protons are polarized, since neutrons with spin anti-parallel to the proton spin are scattered away. L. Shapiro at Dubna proposed to make a polarized slow neutron beam using an LMN filter in 1966.1 Ishimoto et al. made a polarized neutron beam using an ethylene glycol filter at KEK in 1976 [Deregel et al. IV.1980.]. The method was used for parity violation experiments with polarized neutrons of $0.021 \mathrm{eV}$ at Dubna [Dragichesku et al. III.1964], KEK and Los Alamos in 1980s».

\subsection{Renaissance of methods of dynamic polarization at the} turn of the millennium

Research on dynamic polarization continued throughout the 1980s and 1990s in the UK, USA, Switzerland, Japan, and elsewhere. However, in the USSR in the mid-1980s, these studies receded into the background, at the Lebedev Institute and in one of its heirs, the Institute of General Physics of the USSR AS, such studies were no longer resumed, at the Joint Institute for Nuclear Research they dropped to a minimum, at other Institutes they were occasional character. Due to the difficulties in the development of instrumental methods and the limited possibilities for the further growth of human and financial resources for fundamental research, these works began to gradually curtail.

Meanwhile, in the West, another revolution in experimental technology was taking place. Although gyrotron generators of millimeter and submillimeter electromagnetic waves appeared in the USSR, they were widely developed and applied only in Western Europe and in the USA. At the same time, a tendency arose to apply jointly the methods of DNP and sample rotation at a magic angle (MAS) to study a solid. The capability of getting higher induction of magnetic fields continued to grow steadily thanks to the application of superconducting solenoids available for the experiment (see the first DNP research with use of girotron microwave generator of terahertz frequencies in laboratory of Robert Griffin [Becerra et al. IV. 1993]), and the search for new solutions in preparing a sample with a paramagnetic impurity and in setting up the experiment did not stop. Methods for obtaining ultra-low temperatures (for example, using a solution of helium-3 in helium-4) were also improved. The last possibilities were also available in the USSR (in Dubna and Kazan, for example), but the fact is that in Europe and the USA all the numerous new achievements of experimental technology could be used jointly, while in Soviet laboratories they remained available separately. Therefore, at the next stage, scientists from Russia and Georgia could no longer be at the forefront of DNP, and they could only recall their past achievements in studying the problems of spin temperatures and DNP [NMR, EPR and theory of condensed systems of magnetic dipoles. I. 2004]. Along with the growth of experimental possibilities, the DNP method has a powerful and solvent consumer - high-resolution NMR of rare isotopes of organogenic elements carbon and nitrogen, in the first place, as well as of course NMR of protons and phosphorus-31 nuclei in biochemically important substations. Specialists in NMR of complex organic compounds were already backed by their customers - chemical enterprises, pharmaceutical companies and medical institutions.

In particular, the idea arose to use the instantaneous melting of a sample with enhanced in $10^{4}$ and more times polarization nuclei using a laser and transfer the sample to a high-resolution NMR spectrometer ("dissolution DNP" [Ardenkjaer-Larsen et al. IV.2003]), Then, after the operations of multidimensional NMR spectra recording, which were usual by the 2000s, it was necessary to return the sample to the installation to obtain DNP and repeat this field cycling or "shuttle" procedure a sufficient number of times to accumulate signals with a good signal-to-noise ratio.

Finally, at the beginning of the new century, the research team of the Francis Bitter Magnetic Laboratory (FBML) at the Massachusetts Institute of Technology (USA) grew stronger. Since 1992 Robert Griffin has been the head of this laboratory. In 2004, an article [Hu, Grif- 
fin et al. IV. 2004] appeared in which the problem of the influence on the DNP mechanisms of the inhomogeneity of the distribution of paramagnetic centers was solved in the simplest and demonstrable way. The authors were the first to use TEMPO-type biradicals as a paramagnetic impurity to excite DNP. Since then, the arsenal of DNP mechanisms has firmly included the pairwise paramagnetic impurities - biradicals and, accordingly, the mechanism of electron-nuclear cross-relaxation (ENCR), briefly called the cross-effect (CE).

\section{CONCLUSION}

In conclusion, let us recall the main findings from Atsarkin's fundamental review concerning the general state of DNP research in the late 1970s and early 1980s (see also monograph [Atsarkin. II.1980] and, of course, the well-known monograph [Abragam and Goldman. II. 1982]).

1) The spin-spin reservoir model (Provotorov's two-reservoir model) was confirmed. Experiments on dynamic nuclear polarization played an important role in this.

2) A high and in some experiments almost one hundred percent nuclear polarization was obtained, which made it possible to study the dependence on the spins of particles of scattering by protons and deuterons of polarized beams of protons, neutrons and hadrons.

3) Extremely high nuclear polarization made it possible to observe magnetically ordered states of nuclear spins (nuclear ferromagnetism and antiferromagnetism).

We also point out that in early years only in the review and monograph by Atsarkin a special type of DNP mechanism - electron-nuclear cross-relaxation (ENCR) cross-effect (CE) - was discussed. Studies of this mechanism were not completed by that time. In the works of that time, the effects of the spatial inhomogenity of the distribution of paramagnetic centers in the specimen were neglected. Hence, it was unclear what the possible reason for the predominance of this mechanism was. Also, in those years, and perhaps even later, the effect of a bottleneck in DNP, caused by long spin-lattice ESR relaxation times at low temperatures, was not studied in detail.

\section{AKNOWLEDGMENTS}

I would like to express my sincere gratitude to the secretary of the editorial board of the journal Physics Uspekhi, Maria Aksentyeva, for sending the English ver- sion of the review article by Vadim Atsarkin and permission to use the illustrations for this article. Thanks to Dr. W. T. Wenckebach for kindly providing the full texts of his latest published works and photograph. I express my gratitude to Dr.V. V. Ptushenko for the many correction of my article, which serves as a supplement to our joint monograph. I thank in advance the readers who can forgive me for the incompleteness of the information due to technical difficulties and possible errors of the author. I thank Dr. E.B. Feldman for proposition to write this article and Dr. V.A. Atsarkin for extensive help during my scientific work.

\section{NOTES}

1. Some authors believe that in this case there is no actual thermal mixing. However, we will adhere to the concept of V. Atsarkin set out in the text, according to which this is a variant of induced thermal mixing.

2. The transcription of the Russian surname "Lushchikov" ("Loutchikov") causes difficulties (see link below).

3. Japan: KEK-Ko: enerugi: kasokuki kenkyu.kiko: "High Energy Accelerator Research Organization". KEK exists from 1950. 
APPENDIX I GALLERY OF PORTRAITS.

SOME LEADING RESEARCHES WHICH STUDIED THE PHENOMENA CONNECTED WITH SPIN TEMPERATURE AND DYNAMIC NUCLEAR POLARIZATION

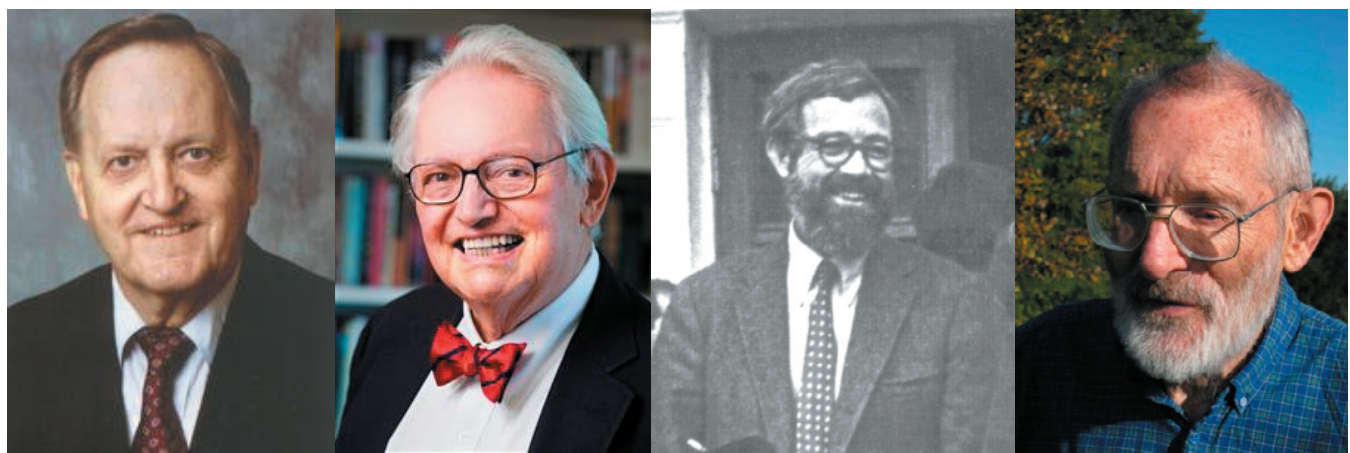

From left to right: Alfred Overhauser (USA, 1925-2011); Charles Slichter (USA, 1929-2019); Carson Jeffries (USA, 1922-1995); Jean Jeener (Belgium, 1933-2016).

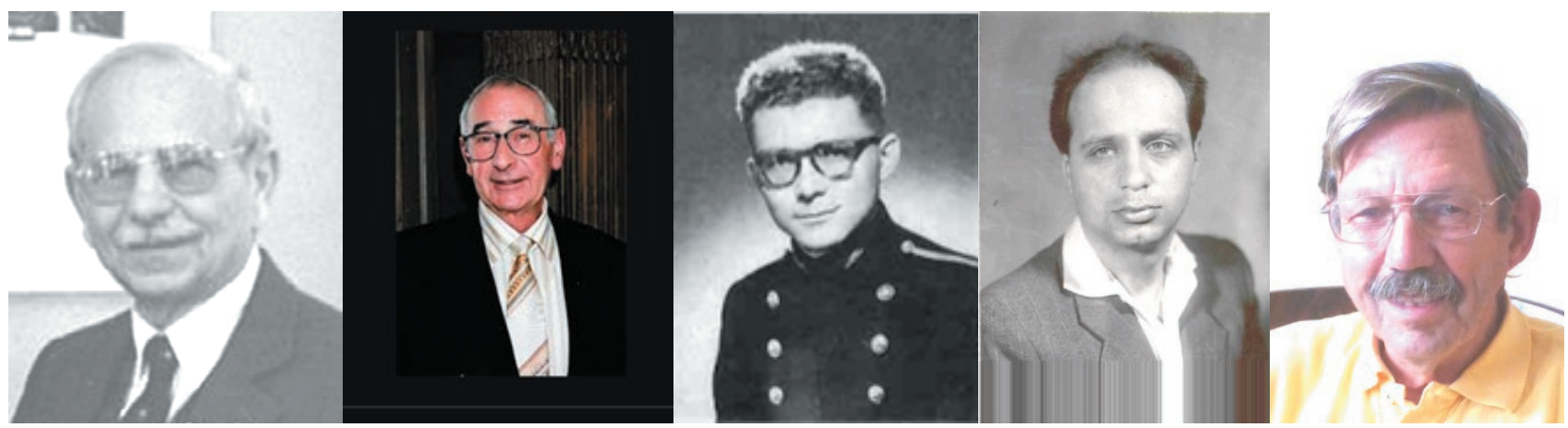

From left to right: Anatole Abragam (France, 1914-2011); Maurice Goldman (France, 1933); Michel Borghini (France, 1934-2012); Vadim Atsarkin (USSR (Russia). 1936); W.T. Wenckebach (Netherland, USA, 1943)

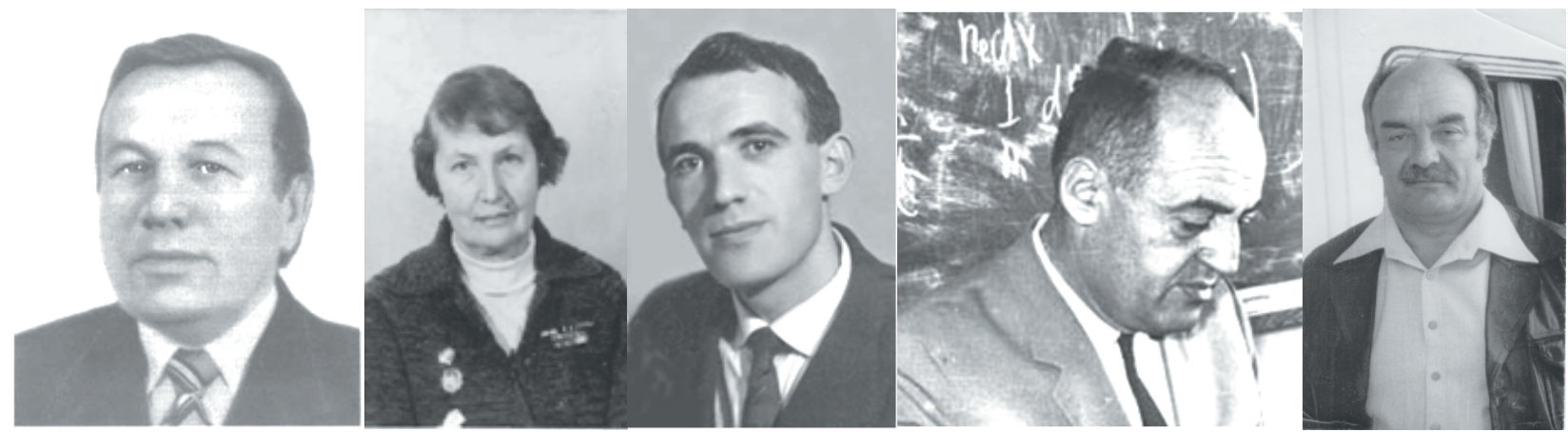

From left to right: Boris Provotorov (USSR (Russia). 1931-2001); Maya Rodak (USSR (Russia.). 1923-2015); Mortko Kozhushner (USSR (Russia). 1937-2020); Givi Khutsishvili (USSR (Georgia). 1921-1969); Levan Buishvili (USSR (Georgia). 1933-1996). 
APPENDIX II.

SELECTED BIBLIOGRAPHY CONSIDERED WORKS DEVOTED INVESTIGATIONS AND APPLICATIONS OF DNP AND SPIN TEMPERATURE MODEL

References (Structured by topics and time)

i. Some abbreviations:

Journal of Experimental and Theoretical Physics: ZhETF - Zhurnal eksperimentalnoy i teoreticheskoy fiziki [Soviet Journal of Theoretic and Experimental Physics - Soviet JETP]

Advances in physical sciences: UFN - Uspekhi fizicheskikh nauk [Soviet Physics Uspekhi ; later Physics Uspekhi]

Journal "Solid state physics": FTT - Fizika tverdogo tela [Sov.Phys. Solid State]

\section{Historical researches and memoires}

1983-1991

Abragam A. Vremya vspyat (ili Fizik, fizik, gde ty byl?) $<$ Backward time (or Physicist, physicist where have you been?)> Moskow: Nauka. Main Redaction of physical and mathematical sciences 1991. 392 s. (Russian variant of Abragam A. Réflexions d'un physicien. Paris: Hermann, 1983.152 p. ISBN: 2-7056-5960-9; ISBN: 978-2-7056-5960-8)

1996

Goldman M. The time when spin temperature was hot stuff//Encyclopedia of NMR. 1996. - ChichesterNew York-Brisbane-Toronto-Singaporo: John Wiley \& Sohns. V.1. P. 338-341

1998

Knight W., Reinolds J., Hahn E., Portis A. Carson Dunning Jeffries (March 22, 1922 - October 18, 1995). Biographical Memoir Copyright 1998 National Academies Press Washington d.c. 15 P. Volume 73 |The National Academies Press (nap.edu). https://nap.edu/ read/9650/chapter/14

2004

EPR, YaMR i teoriya kondensirovannogo sostoyaniya magnitnykh dipoley (opyt ustnoy istorii teorii Provotorova). //Nauchnoe soobshchestvo fizikov SSSR v 1950-e - 1960-e gg. Editors: Vizgin Vl.P.\& Kessenikh A.V. Vyp.1. SPb.: Izd-vo Russian Christian Humanitarian Institute (RKhGI). 2004. S. 300 - 385 [EPR, NMR and the theory of the condensed state of magnetic dipoles (experience of the oral history of Provotorov's theory)]. Scientific community of physicists of the USSR in the 1950s - 1960s. (Russian, recorded by Kessenikh A.V.)
2009

Kessenikh A.V. Magnetic resonance: discovery, investigations, and applications (From the history of physics).H Physics Uspekhi. V. 52, No 7. P. 695-722

2012

Slichter Ch. P. In Memory of Albert W. Overhauser (1925-2011) Applied Magnetic Resonance 2012 volume 43, Issue 1-2. P.3-6: [http://researchgate.net].

Atsarkin V. A. \& Kessenikh A. V. Dynamic Nuclear Polarization in Solids: The Birth and Development of the Many-Particle Concept. Applied Magnetic Resonance,2012. Vol. 43. Issue 1-2. Pp. 7-19 [http:// researchgate.net].

2016

Masaike Akira. Dawn of High Energy Spin Physics In Memory of Michel Borghini Spin Physics (SPIN 2014) International Journal of Modern Physics: Conference Series Vol. 40 (2016) 1660114 (9 pages). (Proceedings of the 21st International Symposium on Spin Physics (SPIN2014); Peking University, China, 20-24 October 2014; Editors: Haiyan Gao and Bo-Qiang Ma - Memorial Session https://doi. org/10.1142/S2010194516601149)

2017

Goldman M. "Anatole Abragam. 15 December $1914-8$ June 2011". Biographical Memoirs of Fellows of the Royal Society.2017. Vol. 63. P.7-21. doi: rsbm.2017.0026. ISSN 0080-4606

2018

Illinois Physics. Charles P. Slichter (1924-2018) https:// physics.illinois.edu/people/memoriale/charles-slichter

\section{Monographs and Reviews}

1961

Abragam A. Principles of nuclear magnetism. Oxford: Clarendon press. $1961.599 \mathrm{p}$

1964

Bilenkiy S.M., Lapidus L.I., Ryndin R.M. Polyarizovannaya protonnaya mishen $\mathrm{v}$ opytakh $\mathrm{s}$ chastitsami vysokikh energiy //UFN. 1964. T. 84, vyp. 2. S. 243-301.

1965

Bilen'kii S.M., Lapidus L.I. , Ryndin R.M. Sov. Phys. Uspekhi. Polarized proton target in experiments with high-energy particles. 1965. Vol.7. P.721-754.

1966

Khutsishvili G.R. Spin diffusion Sov. Phys. Uspekhi, 1966, P. 743-769.

1968

Khutsishvili G.R. Spinovaya diffuziya i yadernaya magnitnaya relaksatsiya $\mathrm{v}$ kristalle, soderzhashchem magnitnuyu primes. UFN. 1968.Vol. 96. P. 441-466. 
1969

Khutsishvili G.R. Spin diffusion and nuclear magnetic relaxation in a crystal containing a magnetic impurity. Sov.Phys. Uspekhi 1969, Vol.11 (6), P.802-815 https://doi.org/10.1070/PU1969v011n06ABEH003776].

Hill D.A., Ketterson J.B., Miller R.C., Moretti A., Niemann R.C., Windmiller L.R., Yokosawa A., Hwang C.F. Dynamic proton polarization in butanol water below 1 K. Phys. Rev. Lett. 1969. V. 23. No 9. P. 460-462.

1971

Noggle J.H., Schirmer R. E. The nuclear OE. Chemical applications. N. Y.- L. Academic Press. 1971. 259 pp

1972

Atsarkin V.A., Rodak M.I. "Temperature of spin-spin interactions in electron spin resonance" Soviet Phys. Uspekhi 1972, Vol.15, P. 251-265

1974

V.A. Atsarkin "Achievements and Current, Problems of Solid-State Radiospectroscopy". Soviet Phys. Uspekhi. 1974. Vol. 16. P. 747-749 (based on the materials of the XVII AMPERE Congress, Turku, Finland, August 21-26, 1972)

1977

Goldman M., « Nuclear dipolar magnetic order1978 ing ", Phys. Rep., 1977. Vol.32, p. 1-67

M. Goldman, A. Abragam, Principles of dynamic nuclear polarisation, Rep.

Progr. Phys. 1978 Vol.41. P.395-467, https://doi. org/10.1088/0034-4885/41/3/002.

Atsarkin V. A. Dynamic nuclear polarization in solids. Sov. Phys.Usp. 1978. 21(9), P. 725 -746.

1979

Pokazanev V.G., Skrotskiy G.V. Psevdomagnetizm [Pseudomagnetism]. UFN. 1979. Vol. 129. № 4. Pp. 615-644.

Pokazan'ev V G, Skrotskii G V "Pseudomagnetism” Sov. Phys. Usp. 1979.Vol.22. P. 943-959.

1980

Atsarkin V.A. Dinamicheskaya polyarizatsiya yader v tverdykh dielektrikakh [Dynamic nuclear polarization in solid dielelectrics]. (Russian). Moskow: Nauka. 1980. 195 p.

1982

Abragam A. \& Goldman M.Nuclear magnetism. Order \& disorder. Oxford: Clarendon Press

2016

Wenckebach T. Essentials of Dynamic Nuclear Polarization. 2016. The Netherlands. Spindrift Publica2019 tions.308 p.

Jannin S., Dumez J.-N., Giraudeau P., and Kurzbach D., Application and methodology of dissolution dynamic nuclear polarization in physical, chemical and biological contexts. J Magn Reson. 2019 June 4; Vol.305: P.41-50. doi:10.1016/j.jmr.2019.06.001.

III. Original researches 1949-1983

1949

Bloembergen N., "On the interaction of nuclear spins in a crystalline lattice," Physica 1949 Vol.15, P. 386-426 1953

Carver T. R., Slichter C.P. Polarization of nuclear spins in metals. Phys. Rev. 1953. Vol. 92. № 1. Pp. 212, 213.

A) Overhauser A. W. Paramagnetic Relaxation in Metals // Physical Review. 1953. Vol. 89. No. 4. P. 689-700.

B) Overhauser A.W. Polarization of Nuclei in Metals. Physical Review. 1953. Vol. 92. № 2. Pp. 411-415.

Portis A.M. Electronic structure of F-centers: saturation of the electron spin resonance // Phys. Rev.1953. V. 91, No 5. P. 1071-1078.

1954

Beljers H. G. L., van der Kint L., van Wieringen J.S. Overhauser effect in free radical. Phys. Rev. 1954. Vol. 95. № 6. P.1683.

Khutsishvili G.R. Spinovaya diffuziya [Spin diffusion]. Tr. In-ta fi z. AN GruzSSR. [Proceedings of Institute for Physics Georgian AS] 1954. Vol. 2. P. 115.

1955

Solomon I. Relaxation Processes in a System of Two Spins. H Physical Review. 1955. Vol. 99. No. 2. P. 559-565.

Redfield AG. Nuclear magnetic resonance saturation and rotary saturation in solids. Physical Review. 1956. Vol.98. P. 1787-1809. DOI: 10.1103/PhysRev.98.1787

Feher G.Method of polarizing nuclei in paramagnetic substances. Phys. Rev. 1956. Vol. 103.No 2. P. $500-$ 501

Feher G., Gere E. A. Polarization of phosphorous nuclei in silicon. Phys. Rev. 1956. Vol. 103.No 3. Pp. $834-$ 835

Solomon I., Bloembergen N. Nuclear Magnetic Interactions in the HF Molecule J. Chem. Phys. 1956.Vol. 25, P.261 - 266. https://doi.org/10.1063/1.1742867

Carver T. R. and Slichter Ch. P. Experimental Verification of the Overhauser Nuclear Polarization Effect. Phys. Rev. 1956. Vol.102, P.975 - 981

1957

Abragam A., Combrisson A., Solomon I. Polarisation nucléaire par effet Overhauser dans les solutions d'ions paramagnétiques. C. R. Acad. Sci. 1957. T. 245, P.157-160.

Jeffries C.D. Polarization of Nuclei by Resonance Saturation in Paramagnetic Crystals Phys.Rev. 1957. Vol.106. P. 164-165. DOI: 10.1103/PhysRev.106.164 
Abraham M., Kedzie R.W. , Jeffries C.D . $\gamma$-Ray anisotropy of $\mathrm{Co}^{60}$ nuclei polarized by paramagnetic resonance saturation. Phys. Rev., 1957. Vol.106, P. 165-166

1958

Abragam A., Proctor W.G. Spin temperature. Phys Rev 1958, Vol.109, No 5. P.1441 - 1457

Abragam, A ., Proctor W Une novelle methode de polarization dynamique des noyaux atomiques dans les solides. Comptes Rendus de l'Academie des sciences. 1958.T. 246. № 14. Pp. 2253-2255.

de Gennes P.G. Sur la relaxation nucleaire dans les cristaux ioniques J. Phys. Chem. Solids, 1958. Vol.7. P. 345-350

Erb E., Motchane J.-L., Uebersfeld J. Sur une nuvelle méthode de polarization nucléaire dans les fluidesadsorbés sur les charbons. Extension aux solides et en particulier aux substances organiques irradiées// Compt. Rend. 1958. T. 246, No 21. P. 3050-3052.

1959

De M.M. Borghini, A. Abragam Polarisation dynamique des protons a de basse temperature Comptes Rendus 1959.T. 248 No 12 pp. $1803-1805$

1960

Müller-Warmuth-W. and Parikh P.Notizen: Overhauser-Abragam-Effekt am $\left(\mathrm{SO}_{3}\right)_{2} \mathrm{NO}^{--}$Radikal in mittleren Magnetfeldern.-Zeitschrift für Naturforschung 1960.A Volume 15: No 1 S. $86-87$

Tchao Y.H., Herve J.Polarisation dynamique des protons d'un radical libre par saturation de la resonance electronique. Compte Rendu 1960. T.250. P. 700 - 706

1961

Borghini M. et Abragam A.. Polarisation dynamique de noyaux (Rapport Comissariat de Energie Atomique $\mathrm{n}^{\circ}$ 1894). 1961. P. 5 (French)

Leifson O. S. and Jeffries C. D. Dynamic Polarization of Nuclei by Electron-Nuclear Dipolar Coupling in Crystals Phys. Rev. 1961. Vol. 122, P.1781 - 1795

Goldman M., Landesman A., " Polarisation dynamique nucléaire par contact thermique entre des systèmes de spins ", C.R. Acad. Sci. 1961, T.252, (), P.263-265

Provotorov B.N. O magnitnom rezonansnom nasyshchenii v kristallakh. ZhETF 1961. Vol. 41. vyp.5. Pp. 1582-1591.

1962

Provotorov B.N. Magnetic resonance saturation in crystals. Soviet Physics JETP. 1962. Vol. 14. № 5. Pp. 1126-1131

Abragam A., Borghini M., Catillon P., Coustham J., Roubeau P., Thirion J., Diffusion de protons polarises de $20 \mathrm{MeV}$ par une cible de protons polarises et mesure preliminaire du parametre $C_{n n}$, Phys. Lett. 1962. T. 2. P. $310-311$.
Provotorov B.N. Kvantovostatisticheskaya teoriya perekrestnoy relaksatsii // ZhETF. 1962.T. 42, vyp. 3. S. 882-888.

Provotorov B. N. A quantum statistical theory of cross relaxation //Soviet Physics JETP 1962. V. 15, No 3. P. 611-614.

Khutsishvili, Spin diffusion and magnetic relaxation of nuclei, Sov. Phys. JETP 1962. Vol.15 ()P.909-913

Goldburg W. J. Static Spin Temperature Experiments and the Approach to Thermal Equilibrium in the Rotating Reference Frame. Phys. Rev. 1962. Vol.128. № 4. P.1554-1561.

1963

M. Goldman and A. Landesman Dynamic Polarization by Thermal Mixing between Two Spin Systems Phys. Rev. 1963. Vol.132, P.610

Kessenikh A.V., Lushchikov V.I., Manenkov A.A., Taran Yu.V. Relaksatsiya i dinamicheskaya polyarizatsiya protonov v polietilenakh. [Relaxation and dynamic polarization of protons in polyethylenes]. FTT 1963, T.5, P.1640-1642

Kessenikh A.V., Lushchikov V.I., Manenkov A.A., Taran Y.V. Proton polarization in irradiated polyethylenes Sov.Phys. Solid State 1963. Vol.5 No 4. P. 641- 649

Khutsishvili G.R. Diffuziya i relaksatsiya protonnogo spina $\mathrm{v}$ obluchennykh polietilenakh. [Diffusion and Relaxation of Proton Spin in Irradiated Polyethylenes]. FTT.1963. Vol. 5. P. 2713-2174.

Hecht R., Redfield A. G. , Overhauser Effect in Metallic Lithium and Sodium. Phys. Rev. 1963. Vol.132, Issue 3. P. $972-977$

Chamberlain O, Jeffries C.D., Schultz C.H., Shapiro G., and van Rossum: Pion Scattering from a Polarized Target. Phys. Lett. 1963. Vol.7, P. 293-295

1964

Philippot J. Spin-Spin Relaxation and Spin Temperatures Phys. Rev. 1964. Vol.133A. P.471 - 477

Kessenikh A.V., Manenkov A.A., Pyatnitskiy G. I. K obyasneniyu eksperimentalnykh dannykh po dinamicheskoy polyarizatsii protonov $\mathrm{v}$ obluchennykh polietilenakh [To explain experimental data on the dynamic polarization of protons in irradiated polyethylenes]. FTT, 1964. Vol. 6. Pp. 827-830.

Kessenikh A.V., Manenkov A.A., Pyatnitskii G.I. On explanation of experimental data on dynamic polarization of protons in irradiated polyethylenes Sov. Phys. Solid State 1964.Vol.6. No 2. P.321 -329

Jeener J., Eisendraht H., Van Steenwinkel R. Thermodynamics of spin systems in solids Phys.Rev. 1964. Vol.133A, № 2. P.478 - 490

Dragichescu B., Lushchikov V.I., Nikolenko V.G.,Taran Yu.V., Shapiro F.L. Neutron polarization by trans- 
mission through a polarized proton target. Phys.Lett. 1964. Vol. 12. Iss. 4. Pp. 334-337.

Rodak M.I. O vozmozhnykh sledstviyakh izmeneniya spin-spinovoy temperatury spinovoy sistemy v tverdom tele [On the possible consequences of a change in the spin-spin temperature of a spin system in a solid]. FTT. 1964. Vol. 6. vyp.2. Pp. 521-528

Rodak M.I. Possible consequences of a change in the spin-spin temperature of a spin system in a solid Sov. Phys. Solid State Vol.6 No 2. P.409 - 415

1965

Buishvili L.L. K kvantovo-statisticheskoy teorii dinamicheskoy polyarizatsii yader [On the quantumstatistical theory of the dynamic polarization of nuclei]. ZhETF. 1965. T.49, no. 6.S. 1868 - 1874.

1966

Buishvili L.L., Contribution to the quantum statistical theory of dynamic polarization, Sov. Phys. JETP 1966. Vol.22. P. 1277-1281.

Franz J. R., Slichter C. R. Studies of perturbation theory and spin temperature by rotary saturation of spins. H Phys. Rev. 1966. Vol. 148, № 1. P.287 - 298

1967

Swanenburg T.J.B., van den Heuvel G.M., Poulis N.J.The influence of the leakage factor on the dynamic polarization of protons in $(\mathrm{La}, \mathrm{Nd})_{2} \mathrm{Mg}_{3}\left(\mathrm{NO}_{3}\right)_{12} .24 \mathrm{H}_{2} \mathrm{O}$. Physica.1967. Vol. 35. P. 369-385

Kozhushner M. A., Provotorov B. N. K vynuzhdennoy dinamicheskoy polyarizatsii yader [To the forced dynamic polarization of nuclei]. Radiospektroskopiya tverdogo tela (Trudy Vsesoyuznogo soveshchaniya, Krasnoyarsk, 1964) [Radiospectroscopy of a solid (Proceedings of the All-Union Conference, Krasnoyarsk, 1964)].(Russian) Moskow.: Atomizdat. 1967. P. 5.

Hwang Ch.F., Hill D.A. New effect in dynamic polarization. Phys. Rev. Lett. 1967. V. 18. No 4. P. 110-112. A

Hwang Ch.F., Hill D.A. Phenomenological model for new effect in dynamic polarization \#Phys. Rev. Lett. 1967. V. 19. No 18. P. 1011-1014. B

Atsarkin V.A., Mefed A.Ye., Rodak M.I. Elektronnaya kross-relaksatsiya i yadernaya polyarizatsiya $\mathrm{v}$ rubine Pisma v ZhETF. 1967. Vol. 6. Pp. 942 - 943.

Atsarkin V.A., Mefeod A.Ye., Rodak M.I. Electron crossrelaxation and nuclear polarization in ruby; JETP Letters. 1967 Vol. 6. Pp 359 - 362.

Atsarkin V.A., Morshnev S.K. Verification of spin-spin Interactions Temperature in EPR. JETP Letters. 1967. V. 6. P. $88-90$.

Rodak M.I. Some physical consequences of dipolar temperature concept in solid state spin systems. Magnetic Resonance and Relaxation (Proc. XIV colloque AMPERE) ed. by R. Blinc, Amsterdam. 1967. P.83 - 84
1968

Atsarkin V.A., Mefeed A.E., Rodak M.I. Electron crossrelaxation and nuclear polarization in ruby. Phys. Letters. 1968.V. 27A, № 1. P. 57-58.

Odehnal M., Loutchikov V.I., Ezratty J. Relaxation et polarisation des cristaux de $\mathrm{La}_{2} \mathrm{Mg}_{3}\left(\mathrm{NO}_{3}\right)_{12} 24 \mathrm{H} 2 \mathrm{O}$ dopé au $\mathrm{Dy}^{3+}$. Journal de Physique, 1968, 29 (10), pp.941-952. $\leq 10.1051 /$ jphys:019680029010094100>. $\leq$ jpa-00206734>

Wenckebach W.Th., Swanenburg T.J.B., Hoogstraate H., Poulis N.J. Non-exponential behaviour of the dynamic polarization of protons in $(\mathrm{Zn}, \mathrm{Cu}) \mathrm{K}_{2}\left(\mathrm{SO}_{4}\right)_{2} .6 \mathrm{H}_{2} \mathrm{O}$. Phys. Lett. Ser. A. 1968, vol. 26, p. $203-204$

1969

Atsarkin V. A., Mefed M. E., Rodak M. I., Sov. Phys. JETP 1969. Vol.28, P.877.

Hill D.A., Ketterson J.B., Miller R.C., Moretti A., Niemann R.C., Windmiller, L.R., Yokosawa A., Hwang C.F. Dynamic proton polarization in butanol water below 1 K. Phys. Rev. Lett. 1969. V. 23. No 9. P. 460-462.

Chapellier M., Goldman M., Yu Hoang Chau, Abragam A. Production et observation d'un état antiferromagnétique nucléaire C.R. Acad. Sci. 1969. T. B268, P.1530-1533. DOI: 10.1051/ jphys:0199000510130147900.

Wenckebach W. Th., van den Heuvel G. M., Hoogstraate H., Swanenburg T. J. B., and Poulis N. J. Experimental Proof of the Strong Coupling Between the Electron Spin-Spin Reservoir and a Nuclear Spin System in Dilute Paramagnetic Crystals Phys. Rev. Lett. 1969. Vol.22, P.581.

1970

Wenckebach W. Th., Swanenburg T. J. B., Poulis N. J.Nuclear dynamic polarization of protons in diluted Copper-Tutton salts. I. Physica, 1970, v. 46, Pages 303-314.

1971

Borghini M., Scheffler K., Experimental evidence for dynamic nuclear polarization by cooling of electron spin-spin interactions, Phys. Rev. Lett. 1971. Vol. 26 P.1 362 - 1365, https://doi.org/10.1103/PhysRevLett.26.1362.

1974

Goldman M., Cox S.F.J., Bouffard V., Coupling between nuclear Zeeman and electronic spin-spin interactions in dielectric solids, J. Phys. C: Solid State Phys. 1974. Vol.7. P.2940-2952, https://doi.org/10.1088/00223719/7/16/021.

Borghini M., de Boer W., Morimoto K. Nuclear dynamic polarization by resolved solid-state effect and thermal mixing with an electron spin-spin interaction reservoir. Phys. Lett. A, 1974. Vol.48, P. 244-246 
Jacquino J.F., Wenckebach W.T., Chapellier M.,Goldman M., Abragam A. Ferromagnetism nucleaire. Compt. Rend. 1974. T. 278B, No 3, P. 93 - 96

1976

Wollan D.S. Dynamic nuclear polarization with an inhomogeneously broadened ESR line I. Theory // Phys. Rev. B. 1976. V. 13, No 9. P. 3671-3685. A

Wollan D.S. Dynamic nuclear polarization with an inhomogeneously broadened ESR line II.Experiment // Phys. Rev. B. 1976. V. 13, No 9. P. 3686-3696. B

1977

van Houten J., Wenckebach W.T., Poulis N.J., A study of the thermal contact between the nuclear zeeman system and the electron dipole-dipole interaction system, Physica. 1977 V.92B. P.210-220, https://doi. org/10.1016/0378-4363(77)90021.

1978

Abragam A., Bacchella G.L., Bouffard V., Goldman M., Meriel P., Pinot M., Roinel Y., Roubeau P. Première observation d'une structure antiferromagnétique nucléaire par diffraction neutronique C. R. Acad. Sci. 1978. T.B286, P.311-314

1980

Deregel J. et al. in Proc. Int. Conf. on High Energy Physics with Polirazed Beam and Targets, p. 463 (1980) Lausanne.

1982

Urbina A C., Jacquinot J.-F., Goldman M. Rotating transverse helical nuclear magnetic ordering Phys. Rev. Lett. 1982. Vol.48, P.206-209

1983

Kazanskii S.A, Atsarkin V.A .Effect of a low-frequency magnetic field on NMR and dynamic nuclear polarization of nuclei in $\mathrm{AI}_{2} \underline{0}_{3}: \mathrm{Cr}^{3+}$ and $\mathrm{CaF}_{2}$ :Tm JETP, 1983 ז., Vol 57, Iss.. 6, P. 1345

\section{Some more later publications}

1986

Atsarkin V.A., Vasneva G.A., Demidov V.V Spin packets and spectral diffusion in a magnetically dilute system with a dipole interaction. JETP, 1986, Vol._64.Iss.4, P. 898

1993

Becerra L. R., Gerfen G. J., Temkin R. J., Singel D. J., Griffin R. G. Dynamic nuclear polarization with a cyclotron resonance maser at $5 \mathrm{~T}$. Phys. Rev. Lett. 1993. Vol.71, P.3561 - 3564

2003

Ardenkjaer-Larsen, J. H.; Fridlund, B.; Gram, A.; Hansson, G.; Hansson, L.; Lerche, M. H.; Servin, R.; Thaning, M.; Golman, K.; Increase in signal-to-noise ratio of $>10,000$ times in liquid-state NMR. Proceedings of the National Academy of Sciences of the United States of America 2003, Vol.100(18), P.10158-10163. 2004

Hu, K. N.; Yu, H. H.; Swager, T. M.; Griffin, R. G. Dynamic Nuclear Polarization with Biradicals. J Am Chem Soc. 2004, Vol.126(35), 10844-10845.

2006

Joo C.-G., Hu K.-N., Bryant J.A., Griffin R.G. In situ temperature jump high-frequency dynamic nuclear polarization. Experiment: enhanced sensitivity in liquid-state NMR spectroscopy//J. Am. Chem. Soc. 2006. V. 128. No 29. P. 9428 - 9431

Song Ch., Hu Kan-Nian, Joo Chan-Gyu, Swager T.M., Griffin R.G. TOTAPOL: A Biradical Polarizing Agent for Dynamic Nuclear Polarization Experiments in Aqueous Media. J. Am. Chem. Soc. 2006. V. 128, No. 35. P. 11385-11390

2008

Golman, K.; Petersson, J. S.; Magnusson, P.; Johansson, E.; Åkeson, P.; Chai, C.; Hansson, G.; Månsson, S. Cardiac metabolism measured noninvasively by hyperpolarized ${ }^{13} \mathrm{C}$ MRI. Magnetic Resonance in Medicine 2008, Vol. 59(5), P.1005-1013.

Prisner T., Köckenberger W. Dynamic Nuclear Polarization: New Experimental and Methodology Approaches and Applications in Physics, Chemistry, Biology and Medicine. Appl. Magn. Reson. 2008. V. 34. P. 213-218.

2010

Lesage A., Lelli M., Gajan D., Caporini M.A., Vitzthum V., Miéville P., Bodenhausen G., Surface enhanced NMR spectroscopy by dynamic nuclear polarization. Journal Am. Chem. Soc. 2010. Vol.132 (44), P.1545915461

2011

Hu K.-N., Debelouchina G.T., Smith A.A., Griffin R.G. Quantum mechanical theory of dynamic nuclear polarization in solid dielectrics J. Chem. Phys. 2011. Vol. 134.No 12. P. 125105-1 - 125105-19

Hovav Y., Feintuch A., Vega S. Dynamic nuclear polarization assisted spin diffusion for the solid effect case J. Chem. Phys., 134 (2011), P. 074509

2012

Hovav Y., Levinkron O, Feintuch, A., Vega S.Theoretical Aspects of Dynamic Nuclear Polarization in the Solid State: The Influence of High Radical Concentrations on the Solid Effect and Cross Effect Mechanisms Applied Magnetic Resonance 2012.Vol. 43,No 1/2, P.21-41

A. Karabanov, G. Kwiatkowski, W. Köckenberger Quantum mechanical simulation of cross effect DNP 
using Krylov-Bogolyubov averaging. Appl. Magn. Reson., 2012. Vol. 43. P. 43-58

2017

Wenckebach W.T., Dynamic nuclear polarization via thermal mixing: beyond the high temperature approximation, J. Magn. Res. 277 (2017) 68-78, doi. org/10.1016/j.jmr.2017.01.020.

Pylaeva S., Ivanov K.L., Baldus M., Sebastiani D., Elgabarty H. Molecular mechanism of Overhauser dynamic nuclear polarization in insulating solids. J. Phys. Chem. Lett., 2017. Vol.8 , P. 2137-2142

2019

Wenckebach W.Th. Dynamic nuclear polarization via the cross effect and thermal mixing:

A. The role of triple spin flips Journal of Magnetic Resonance. 2019. Vol.299. P. 124-134

W.Th. Wenckebach Dynamic nuclear polarization via the cross effect and thermal mixing:

B. Energy transport Journal of Magnetic Resonance 2019. Vol.299. P. 151-167 